\title{
Strength analysis and optimization of writing mechanism of steel billet marking machine
}

\author{
Min $\mathrm{Fu}^{1,2}$, Yan $\mathrm{Li}^{1,2, *}$, and Liang Zhao ${ }^{1}$ \\ ${ }^{1}$ College of Mechanical Engineering, Tianjin University of Science \& Technology, Tianjin, 300222, P.R. China \\ 2 Tianjin Key Laboratory of Integrated Design and Online Monitoring for Light Industry \& Food Machinery and Equipment, Tianjin, \\ 300222, P.R. China
}

\begin{abstract}
According to steel billet marking theory of plasma arc nicking, the paper designs a dual laser ranging marking machine against online marking of special steel billet and realizes multi-character marking of the end face of hot steel billet. Writing mechanism bases on the rectangular coordinates marking form, $Z$ axis adopts cantilever structure. It completes the overall marking task utilizing the synergy of KK module in $\mathrm{X}$ axis, $\mathrm{Y}$ axis and $\mathrm{Z}$ axis. It makes modal analysis on the writing mechanism model established by Pro/Enginner utilizing ANSYS Workbench at the position of X1Y1Z1, and obtains the first six order modal frequency and analyzes the vibration in the writing process. Moreover, the paper analyzes the static structure of the cantilever of writing mechanism, computes its maximum stress and total deformation. To make the writing mechanism reach the target of light weight, the paper optimizes Z-axis cantilever of writing mechanism. According to the analysis, it is known that the optimized Z-axis cantilever of the writing mechanism still meets the strength and rigidity requirement and total mass declines approximately $30 \%$.
\end{abstract}

\section{Introduction}

Steel billet marking machine is one of important machines for the production of steel enterprise. To facilitate management of production and quality of steel works, the steel enterprise usually marks the steel billet product and marks the sole number composed of related information on the surface of steel billet. If quality problem occurs, the continuous casting machine number, furnace number, serial number, time and other important information of steel billet can be traced according to the mark number so as to discover and solve the machine problem earlier [1]. Hereinto, writing mechanism is an important component of steel billet marking machine. It provides movement basis for the steel billet marking machine, so the position accuracy of writing mechanism must be guaranteed. The steel billet marking machine on the continuous casting line of special steel billet designed in the paper utilizes dual laser ranging system to prevent the mobile box colliding with the steel billet of writing mechanism. Writing mechanism is installed in the mobile box. It applies PLC to control servo motor and drive KK module and makes the movement of writing mechanism to complete the marking work. Kinetics and strength feature of writing mechanism affects the effect and stability of steel billet marking machine and prevents serious vibration of writing mechanism in the operation. Thus, it is necessary to analyse the static structure and modality of writing mechanism [2]. Meanwhile, considering economy and performance requirement, the paper makes optimal design of writing mechanism on the premise of meeting the strength and use requirement.

\section{Determine writing mechanism structure and build 3D model using Pro/E}

Marking device needs to mark on the end face of hot steel billet, defines the length direction of steel billet as $\mathrm{Z}$ axis, the plane vertical to it is $\mathrm{XY}$ plane (namely writing plane). Servo motor and uniaxial robot are installed in XYZ axes to drive the movement of spearhead, and one or two ancillary slide ways are installed in XYZ axes to support and assist the movement, which enhances the rigidity of writing mechanism.

The quality consistence of end surface of steel billet after cutting is poor, and there is a certain cutting slope (about $1.5^{\circ} \sim 2.5^{\circ}$ ). The movement of Z-axis KK module is used for compensating the distance deviation caused by cutting inclination. $\mathrm{Z}$ axis adopts cantilever structure. Plasma spearhead and spearhead protection mechanism are hung on the Z-axis support through rectangular beam and rectangular structure to make the component which is easily affected by the temperature be far away from the writing position of spearhead. The paper makes 3D

Corresponding author: 1632366977@qq.com 
modeling using Pro/E and the writing mechanism is shown in Fig. 1.

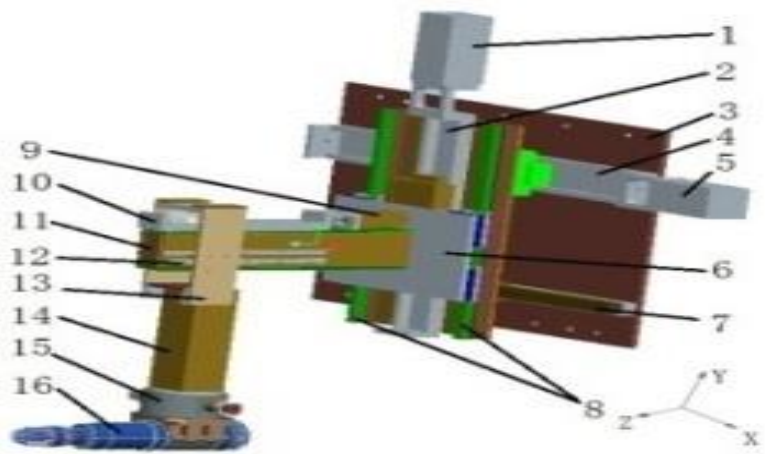

1. Y-axis motor 2. Y- single axis robot 3. X-baseplate 4. Xsingle axis robot 5 . $\mathrm{X}$-axis motor 6 . Z-baseplate 7 . X-ancillary guideway 8 . Y-ancillary guideway 9 . Z-axis motor 10 . Asingle robot 11. Z-support 12. Z-ancillary guideway 13 . Rectangular structure 14. Vertical beam 15. Spearhead protection mechanism 16. Plasma spearhead

Fig. 1. Structure chart of writing mechanism.

\section{Modal analysis of writing mechanism}

The working of writing mechanism is that servo motors in the axis of $\mathrm{XYZ}$ drive $\mathrm{KK}$ module to realize coordination movement in these three directions. A certain vibration occurs in the writing process. To prevent the motivation of writing mechanism and servo motor causing low-order frequency resonance and affecting marking, or even damaging spearhead, it is necessary to analyse the inherent frequency and mode of vibration of writing mechanism [3, 4]. The stroke of KK module is controlled through proximity switch. When the sliding block of writing mechanism is located in the middle point of stroke, recording it as X1Y1Z1 position. The paper utilizes ANSYS Workbench to make modal analysis of writing mechanism in the position of X1Y1Z1, analyses, solves and extracts the first 6-order modality, as shown in Fig. 2. Table 1 is the description of inherent frequency and mode of vibration of various order modalities.

According to the following table, it is known, the inherent frequency $60.01 \mathrm{~Hz}$ of second-order modality approximates to inherent frequency $62.79 \mathrm{~Hz}$ of thirdorder modality, but the maximum amplitude occurs in different positions. Maximum amplitude of the secondorder modality occurs at the Y-axis motor end, but maximum amplitude of the third-order modality occurs at the front end of spearhead. According to mode of vibration diagram of modal analysis, it is known, the nearer the centre of gravity of the writing mechanism is to the distance of fixed end and that of symcenter of structure, the better the rigidity of the whole system is and the higher the inherent frequency is. Thus, during marking, Z-axis sliding block should close to the drive motor, and sliding block in $\mathrm{X}$ axis and $\mathrm{Y}$ axis should close to the midpoint of stroke so as to increase system rigidity of writing process and reduce the possibility of resonance occurrence. The inherent frequency of minimum first order of writing mechanism is $43 \mathrm{~Hz}$, but the maximum of exciting force frequency of motor when writing is only $11.1 \mathrm{~Hz}$. It indicates that the rigidity of writing mechanism is very good and the possibility of system producing resonance in the marking process is very small.

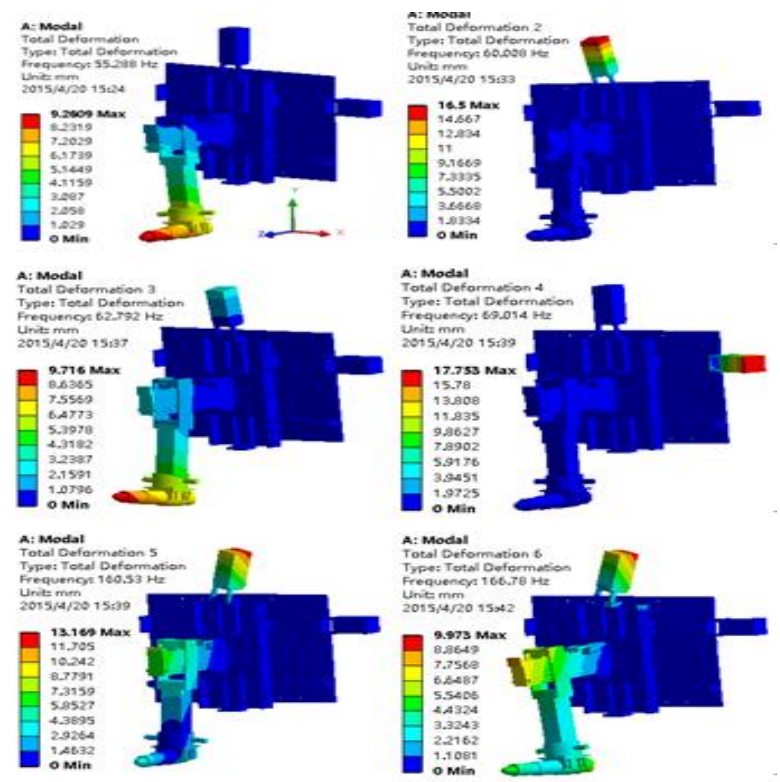

Fig. 2. The modal analysis results of location X1Y1Z1.

Table 1. Modal frequencies and mode shapes of location $\mathrm{X} 1 \mathrm{Y} 1 \mathrm{Z1}$.

\begin{tabular}{|c|c|c|c|c|c|c|}
\hline Order & 1 & 2 & 3 & 4 & 5 & 6 \\
\hline $\begin{array}{c}\text { Inherent } \\
\text { frequency } \\
\mathrm{HZ}\end{array}$ & 55.29 & 60.01 & 62.79 & 69.01 & 160.53 & 166.78 \\
\hline $\begin{array}{l}\text { Mode } \\
\text { of } \\
\text { vibration }\end{array}$ & $\begin{array}{l}\mathrm{T} \text { h e } \\
\text { cantilever } \\
\text { o f } \\
\text { spearhead } \\
\text { swing } \\
\text { around } \\
\mathrm{Z} \text { axis }\end{array}$ & $\begin{array}{c}\mathrm{T} \text { h e } \\
\text { cantilever } \\
\text { o f } \\
\text { spearhead } \\
\text { and } \\
\text { motor } \\
\text { end } \\
\text { in } \\
\mathrm{Y} \text { axis } \\
\text { swing } \\
\mathrm{s} \\
\text { around } \\
\mathrm{X} \text { axis }\end{array}$ & $\begin{array}{c}\text { T h e } \\
\text { cantilever } \\
\text { o f } \\
\text { spearhead } \\
\text { and } \\
\text { motor } \\
\text { end } \\
\text { in } \\
Y \text { axis } \\
\text { swing } \\
\text { around } \\
X \text { axis }\end{array}$ & $\begin{array}{l}\mathrm{Th} \text { e } \\
\text { motor } \\
\text { end } \\
\text { in } \\
\mathrm{X} \text { axis } \\
\text { bends } \\
\text { toward } \\
\mathrm{Y} \text { axis }\end{array}$ & $\begin{array}{c}\mathrm{T} \text { h e } \\
\text { cantilever } \\
\text { o f } \\
\text { spearhead } \\
\text { and } \\
\text { motor } \\
\text { end } \\
\text { in } \\
Y \text { axis } \\
\text { swings } \\
\text { around } \\
Y \text { axis }\end{array}$ & $\begin{array}{l}\text { T h e } \\
\text { cantilever } \\
\text { of } \\
\text { spearhead } \\
\text { and } \\
\text { motor } \\
\text { end } \\
\text { in } \\
\text { Y axis } \\
\text { swings } \\
\text { around } \\
\text { and } \\
\text { bend } \\
\text { toward } \\
Z \text { axis }\end{array}$ \\
\hline
\end{tabular}

\section{Static structure analysis of cantilever of writing mechanism}

\subsection{Establishment of Z-axis cantilever structure of writing mechanism}

Z-axis cantilever of writing mechanism is composed by welding seven pieces of plates. All the plates in the initial design is made from Q235 steel, the boundary dimension of cantilever structure is $474 \times 60 \times 100 \mathrm{~mm}$, the thickness of rib plate is $3 \mathrm{~mm}$ and the thickness of other 
plates is $8 \mathrm{~mm}$. Z-axis cantilever structure is shown as Fig. 3. (The figure is $1 / 2$ structure.)

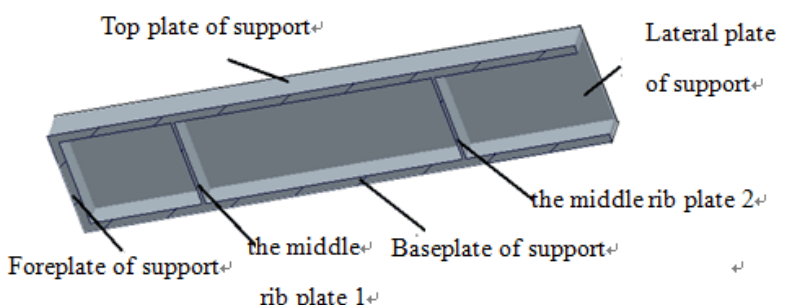

Fig. 3. The structure diagram Z- cantilever beam.

\subsection{Characteristic parameter of material}

Cantilever structure is processed using spot welding and molding. The characteristic parameter of material is shown in Table 2.

Table 2. Z-axis cantilever material parameter.

\begin{tabular}{|c|c|c|c|c|c|}
\hline Grade & $\begin{array}{c}\text { Ela stic } \\
\text { modulus } \\
/ \\
\mathrm{MPa}\end{array}$ & $\begin{array}{c}\text { Poisson } \\
\text { ratio }\end{array}$ & $\begin{array}{c}\text { Density } \\
/ \\
\left(\mathrm{kg} / \mathrm{mm}^{3}\right)\end{array}$ & $\begin{array}{c}\text { Yield } \\
\text { strength } \\
/ \\
\mathrm{MPa}\end{array}$ & $\begin{array}{c}\text { Tensile } \\
\text { strength } \\
/ \\
\mathrm{MPa}\end{array}$ \\
\hline Q235 & $2 \times 10^{5}$ & 0.3 & $7.85 \times 10^{-6}$ & 235 & $375-460$ \\
\hline
\end{tabular}

\subsection{Finite element analysis and computation}

\subsubsection{Apply load and boundary condition}

The front end of Z-axis cantilever is connected to spearhead structure, so the axial load is applied to the front end of cantilever, the measured axial load is $\mathrm{F} 1=468 \mathrm{~N}$. In addition, the self-gravity is $\mathrm{F} 2=312 \mathrm{~N}$. The back end of $\mathrm{Z}$-axis cantilever is fixed on the $\mathrm{Z}$-axis support, so fixed constraint is applied to the back end.

\subsubsection{Compute the stress and deformation of Z-axis cantilever of writing mechanism}

The horizontal plate, lateral plate and rib plate of writing mechanism is made of Q235 steel plate through spot welding and molding method. The paper applies load and constraint condition so as to compute the equivalent stress and total deformation nephogram, as shown in Fig. 4.

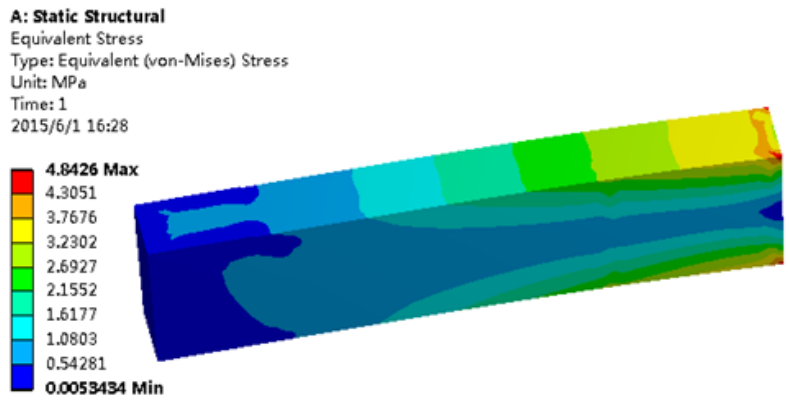

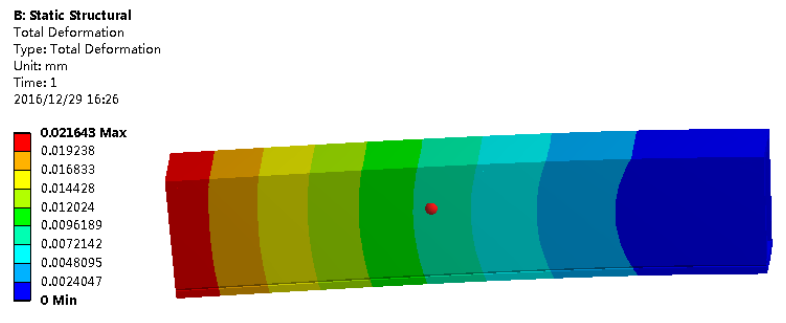

Fig. 4. Deformation and equivalent stress nephogram of Z-axis cantilever.

\subsubsection{Result analysis}

According to equivalent stress and total deformation nephogram, it is known the maximal deformation and maximal equivalent stress of $Z$-axis cantilever of writing mechanism. The maximal deformation of $Z$-axis cantilever of writing mechanism occurs at the front end of cantilever, the maximum deformation is $\delta \max =$ $0.0216 \mathrm{~mm}$, the maximum stress occurs at the joint of back end of cantilever and maximum stress is $\sigma$ $\max =4.84 \mathrm{Mpa}$. Considering that the spearhead must be accurate when writing mechanism works, so the deformation cannot be too big. Thus, the design structure meets the requirement of maximum deformation. Combining with the above factors and actual cases, the cantilever made of Q235 steel plate using spot welding and molding method has good performance. We take safety factor of yield strength as $\mathrm{n}=2$, and allowable stress as $[\sigma]=\sigma \mathrm{s} / \mathrm{n}=235 / 2=117.5 \mathrm{MPa}>4.84 \mathrm{MPa}$, so the strength and rigidity of cantilever made of Q235 steel plate suing spot welding and molding method conforms to the requirement and it has great safety margin, so it only needs to ensure the welding quality. The design has great design margin, so it is necessary to make optimal design.

\section{Optimal design of cantilever of writing mechanism}

\subsection{Theoretical basis of optimal design}

The structure size of cantilever of writing mechanism is optimized using Design Explorer in ANSYS Workbench and multi-objective optimization function. Hereinto, the optimal design made by Design Explorer is achieved through response surface (line) and the fitting of response surface (line) is completed through design point $[5,6]$. Through determining the establishment of multiobjective optimization function, the paper calls in goal driven optimization for Design Explorer optimization design of structure size of connecting plate.

\subsection{Establishment of optimal design}




\subsubsection{Establishment of multi-target optimization function}

Other components of writing mechanism is standard component and the design margin of the height of cantilever and thickness of plate is great, so optimizing the cantilever of writing mechanism can reduce the weight. The weight can be reduced from boundary dimension of cantilever and the thickness of the used plate. The width and length of cantilever are related with the corresponding KK module, so the paper selects height of cantilever (P2) and thickness of plate (P1) as the input parameters and takes mass P6 and equivalent stress P4 as the optimized output parameter so as to reduce the mass of cantilever of writing mechanism and establish multi-objective optimization function, as shown in Formula (1):

$$
\begin{aligned}
& \operatorname{Min} \mathrm{f}(X)=P 6 \\
& \mathrm{X}=[x 1, x 2]=[P 1, P 2] \\
& \text { s.t. } \sigma<=P 4=117.5 \mathrm{Mpa} \\
& 5 \mathrm{~mm}<=P 1<=8 \mathrm{~mm} \\
& 70 \mathrm{~mm}<=P 2<=100 \mathrm{~mm}
\end{aligned}
$$

In the formula, $\mathrm{P} 1$ is the thickness of cantilever plate; P2 is the height of cantilever; P4( $\sigma$ max) is the equivalent stress; $\mathrm{p} 6(\mathrm{~m})$ is mass (the below is the same).

\subsubsection{Call in and compute goal driven optimization}

The paper optimizes parameter using Response Surface in the optimization module so as to observe the impact of the change in each design point on the optimal target. Through 2D curve and 3D curve, it is seen the response of each design point to the optimal target. The optimization target and importance of each parameter can be set up according to the impact of input parameter on output parameter. The impact of the plate thickness $\mathrm{P} 1$ and height $\mathrm{P} 2$ of cantilever of writing mechanism on mass P6 and maximum stress of cantilever of writing mechanism is shown as the generated response surface in Fig. 5.

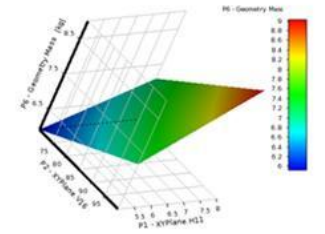

The varies of mass p 6 with plate thickness $\mathrm{p} 1$ and height $\mathrm{p} 2$.

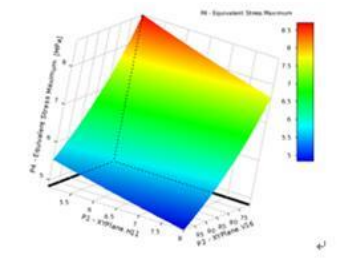

The varies of maximum stress p6 with plate thickness $\mathrm{p} 1$ and height $\mathrm{p} 2$.*
Fig. 5. Response surface of parameters.

Through analyzing response surface, it is known, the structural mass P6 increases with the increasing of height P1 and plate thickness p2 of cantilever, but the corresponding equivalent stress $\mathrm{P} 4$ decreases accordingly. So does the actual situation. With the increasing of the plate thickness and section of cantilever, the bearing capacity increases, structural mass also increases. When bearing the same load, the stress value and deformation also decrease. The impact of plate thickness and height on the cantilever is almost the same. The impact of height of cantilever on the equivalent stress is greater than the plate thickness on it. That is, the impact of $\mathrm{P} 1$ and $\mathrm{P} 2$ on $\mathrm{P} 4$ and $\mathrm{P} 6$ is $\mathrm{P} 1<\mathrm{P} 2$.

Goal driven optimization result ensures minimum mass and minimum maximal deformation and updates new response point after optimization. After analysis and comparison, the paper selects response point as the final optimization result, namely taking $\mathrm{P} 1=6 \mathrm{~mm}$ and $\mathrm{P} 2=70 \mathrm{~mm}$ to generate model and analyze its maximum stress. The parameters comparison before and after optimization are shown in Table 3.

Table 3. Parameter change comparison of cantilever of writing mechanism before and after optimization.

\begin{tabular}{|c|c|c|c|c|}
\hline $\begin{array}{c}\text { Parameter } \\
\text { name }\end{array}$ & $\begin{array}{c}\text { Thickness } \\
\text { of } \\
\text { cantilever } \\
\text { beam } \\
\mathrm{P} 1 / \mathrm{mm}\end{array}$ & $\begin{array}{c}\text { Height } \\
\text { of } \\
\text { cantilever } \\
\text { beam } \\
\mathrm{P} 2 / \mathrm{mm}\end{array}$ & $\begin{array}{c}\text { Maximum } \\
\text { mass } \\
\mathrm{P} 2 / \mathrm{kg}\end{array}$ & $\begin{array}{c}\text { Maximum } \\
\text { stress } \\
\mathrm{P} 4 / \mathrm{MPa}\end{array}$ \\
\hline $\begin{array}{c}\text { Before } \\
\text { optimization }\end{array}$ & 8 & 100 & 31.2 & 4.84 \\
\hline $\begin{array}{c}\text { After } \\
\text { optimization }\end{array}$ & 6 & 70 & 21.8 & 8.50 \\
\hline
\end{tabular}

\section{Conclusions}

The marking effect chart of cantilever of writing mechanism before and after optimization is shown as Fig. 6 when the whole steel billet marking machine is produced, processed and assembled at the factory. From the figure, it is seen, the character written by the writing mechanism before optimization has obvious "shaking" phenomenon, and the character line is not smooth. Writing mechanism can complete the marking content, but the strokes of character it marks loses stability seriously and the marking effect is not good; but the character stroke marked by the writing mechanism after optimization is neat and smooth and the marking effect is improved greatly, which proves that the optimization effect is obvious.
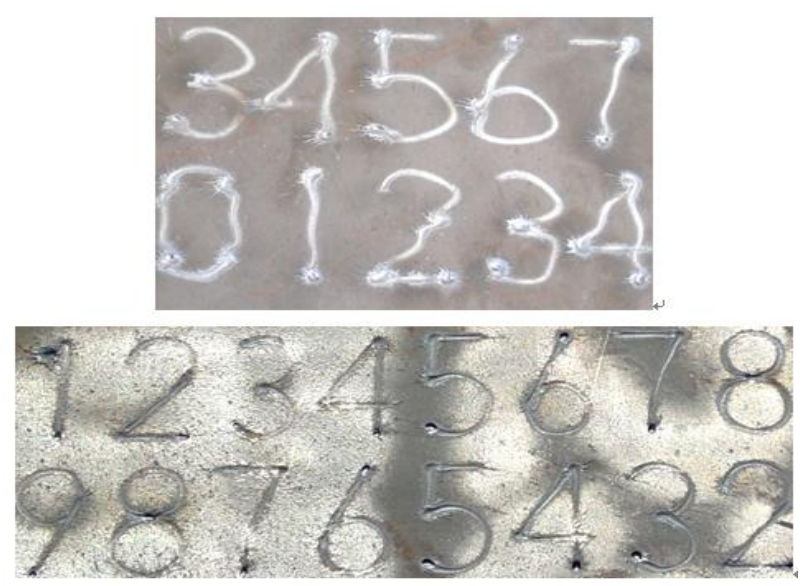

Fig. 6. Comparison of marking effect. 
The paper analyzes the inherent modality of writing mechanism in common working position X1Y1Z1 and the writing mechanism will not have strong vibration phenomenon in the marking processes. To make mass of the structure lightest and most rational and ensure the rigidity and strength of structure, the paper makes optimal design of the size and maximum stress of Z-axis cantilever structure of writing mechanism made from Q235 steel plate through welding and molding:

(1) After finite element static structure analysis, it is found, the deformation of Z-axis cantilever structure of writing mechanism made from Q235 steel plate through welding and molding is small. It meets the strength and rigidity requirements and has great safety margin.

(2) After optimal design, the plate thickness of cantilever of writing mechanism is reduced and the height is reduced greatly, which reduces the mass of cantilever of writing mechanism from $31.2 \mathrm{~kg}$ to $21.8 \mathrm{~kg}$, about $30 \%$. On the condition of meeting requirement, maximum stress increases little and has a certain safety margin. It achieves the target of lightest and most rational structural mass and reduces the cost.

\section{References}

1. X.Y. Jiang, Z.Q. Xiang, J.X. Liang, Industrial Design, 29, 4, 191-194 (2001)

2. M. Fu, Q.X. Song, Journal of Tianjin University of Science \& Technology, 4, 54-59 (2014)

3. M. Fu, L.F. Lin, Y. Liu, Manufacturing Automation, 11, 6, 49-51 (2015)

4. X. M. Song, J. J. Cui, X. L. Li, Machinery Design \& Manufacture, 3, 103-106 (2016)

5. B. Li, Z.J. He, X.F. Chen, ANSYS Workbench design, simulation and optimization (Tsinghua university Press, Beijing, 2013)

6. J.B. Chen, Y. Yang, Method of Optimization (China Sinopec Press, Beijing, 2010) 